\title{
Enhancing business entrepreneurship through open government data
}

\author{
Nazem Mahmoud Malkawi ${ }^{a^{*}}$, Akif Lutfi Al-khasawneh ${ }^{\mathrm{b}}$ and Mohammad Haider Sadeq Mohailan ${ }^{\mathrm{c}}$
}

a Jadara University-Jordan, Research and Studies Center, Riyadh, Saudi Arabia

${ }^{b}$ Alhoson-Al-Balqa Applied University, Jordan

cInstitute of Public Administration, Riyadh, Saudi Arabia

\section{H R O N I C L E}

Article history:

Received: July 20, 2020

Received in revised format:

September 102020

Accepted: October 5, 2020

Available online:

October 8, 2020

Keywords:

Business Entrepreneurship

Entrepreneurs

Jordan

Open Government Data

Small and Medium Enterprises

\section{A B S T R A C T}

Small and medium enterprises play a very important role in today's economy and contribute heavily on a national economy specially in developing countries like Jordan, but they are still facing many challenges, and need support from government specially in data availability. This study aimed to know the impact of open government data (OGD) on business entrepreneurship from Jordanian Irbid State entrepreneurs' point view. To achieve this, (600) questionnaires were distributed to the sample of Jordanian entrepreneurs in Irbid state and (536) valid questionnaires were recovered. The study indicates that OGD and entrepreneurship had a moderate level. There is a significant statistical effect of OGD on business entrepreneurship $(\alpha \leq 0.05)$ in Jordanian SMEs Irbid state. At the end researchers recommend government and entrepreneurs to adopt OGD as a strategy to maximize benefits gained from open government data strategy, improve the quality of published data, and recommended entrepreneurs to increase the level of relying on OGD to get information about materials, markets, competitors, legislations and so on to get benefits for their companies.

(C) 2021 by the authors; licensee Growing Science, Canada

\section{Introduction}

With the advent of advanced technology and increased of its capacity to store and process data with the ability to search in it (Malkawi, 2016), the concept of open data emerged as a powerful tool, through which governments could achieve economic development and reinforce the rational governance. As a result, the data has become an expensive commodity and important capital asset, so governments have tended to adopt an open data approach, and developed strategies and plans to facilitate the benefits from the data revolution in achieving sustainable development. Governments, civil society organizations, and the private sector also aware the importance of this approach, which is based on disseminating government data and making it available for public via Internet for use and reuse by all society sectors. Many studies indicate that, most open data initiatives did not achieve their objectives well, because they do not take users' point of view into account, and the lack of using open government data. Researches indicated that open government data policy has many benefits, including: increasing the ability of governments to make new policies, engaging citizens, developing knowledge, increasing community participation, and many economic benefits like increasing competitiveness, improving the quality of products and services, reducing government spending, and stimulating creativity (Zuiderwijk et al., 2018; Deloitte, 2017; Malkawi, 2018). Therefore, any organization or industry regardless of its size will face countless challenges internally and externally, so, it is either struggling these challenges to survive and cope with the speed of progress and entrepreneurship, or melting and go out from market irreversibly.

Based on the above, entrepreneurship comes to open many opportunities for entrepreneurs and innovators. It is one of the most important economic forces the humanity known in the history; it enables individuals to search for opportunities where

* Corresponding author.

E-mail address: n malkawi@hotmail.com (N. M. Malkawi) 
others find it as intractable problems. Entrepreneurship is a symbol of perseverance and achievement, and vital source of change in all aspects of society (Pahuja \& Sanjeev, 2019). Entrepreneurship and innovation are essential and applicable tools in all aspects of life, it is not exclusive for the developed countries, and not as the belief that entrepreneurship and innovation are only for the prerogatives of the business community and the smart ones, it is not also just the arrogance of the people of the developed world to believe that they are the origin and source of all knowledge, and that entrepreneurship is limited only to some social classes (Cowdrey, 2018); it is an opportunity and the core of many economies in developing countries, and thousands of entrepreneurs establish thousands of progressive small and medium enterprises (SMEs) in these countries which need support from governments. All of this prompted researchers to conduct this study in an environment that relies heavily on SMEs as a result of the declining government role in employment in the public sector, lack of resources, and poor financial conditions.

\section{Importance of the Study}

In light of the global openness, ease of transmission and communication between countries and people, the spread of knowledge, the potentials for trade and industry around the globe, and with the vast resources of rich and industrialized countries and scarcity in poor countries, business entrepreneurship and SMEs become a vital strategy to deal with these difficulties. Jordan is one of developing countries which suffers from many difficulties like lack of natural resources, succession of crises and migrations from neighboring countries, and suffering from heavily debts, which made Jordan as one of the poor countries in the world. The availability of creative human resources (Malkawi et al., 2018) has enabled to establish SMEs that make a positive contribution to the national economy and reduce unemployment. Also, Jordan is going through difficult economically times, the business environment is not conducive for many businesses, and not to mention the unstable situation in the Middle East, as a result many large companies are closing down while others are downsizing. Therefor SMEs have become the most important actor in today's national economy; and these SMEs need support through legislations, money, reduce taxes, data, and other initiatives to encourage this sector. They are considered as one of the important sources for innovation and creation, and government depends on them to reduce unemployment, poverty, and raising the citizens' economic level, then economic position for the country as a whole. However, these businesses still do not have the experience to compete and grow in developing countries in general, and Jordan specially is one of these countries. These SMEs have no ability to accumulate data and knowledge, and no ability to buy and collect data, it is a new sector and needs to be supported, data is one of the major source to support these companies, therefor the availability of government data gives these entrepreneurial businesses and entrepreneurs a main source to compete and success through innovation, integration, marketing and so on. This needs to be studied, therefore, this study will show how open government data (OGD) affects entrepreneurial businesses in Jordan.

\section{Problem Statement}

SMEs face many challenges in today's business and one of these challenges is government data availability. Governments use many tools to publish their data for the benefit of private and public organizations, people, entrepreneurial businesses and entrepreneurs, civil service organizations and so on. The level of open government data in Jordan and its effect on entrepreneurial businesses and entrepreneurs is a big issue, which needs to be studied and measured. Therefor the problem of this study comes from studying the effect of open government data on entrepreneurial businesses in Jordan from Jordanian Irbid State Entrepreneurs' point view, so the study problem tries to answer the following question:

What is the effect of open government data on business entrepreneurship from Jordanian Irbid State entrepreneurs' point view?

Research on this topic and explore open government data and its effect on entrepreneurial businesses is very important issue in Jordanian (SMEs) to sustain and achieve competitive advantage.

\section{Literature review}

\subsection{Open government data (OGD)}

\subsubsection{Definition and importance of government data}

Government institutions, such as ministries, public organizations, municipalities and others, produce and collect huge amounts of data during their work covering various aspects of life, such as health, legal, transportation, national statistical data, financial statements, laws, regulations, etc. The use of such data for a specific purpose does not preclude its use for other purposes in non-governmental organizations, civil society organizations and the private sector. Many countries, especially developed ones, have realized the importance of this, and have made strides in this area, such as the United States of America, Britain, Germany and others. The importance of open government data stems from its ability to achieve many benefits at the national level, such as economic benefits, citizen participation and the quality of government services. In addition, the availability of data to end-users, will enhance decision-making, active participation, and evaluation of various development programs. So many economic analyses showed the benefits gained from the private sector when using open government data, whether through the emergence of a large number of entrepreneurial businesses and SMEs, increasing the efficiency and effectiveness of operations, or in the form of creating new products and services to the market, which increases the volume of private sector 
activity, then revitalize the national economy in general. Therefore, governments seek to adopt open data approaches to increase transparency, participation and cooperation, then encourage innovation and achieve higher economic values. Many studies indicated that the availability of reusable government data leads entrepreneurs to benefit from it in their businesses whether in marketing, supply chains, innovation or to deal with everyday issues facing their SMEs (World Bank Summit for Open Data 2012-2017). Questions remain about this new concept, what is the optimal government strategy for open data? Why do some governments succeed in adopting an open data approach while others fail and continue to suffer? How does open data contribute to increase citizen confidence, participation and exploit it in economic development? Social networks and digital mobile devices have facilitated the creation of new services through easy access to data, analysis and utilization of it at anytime and anywhere (Malkawi \& Halasa, 2016). Countries, which adopt this approach build the necessary strategies and adopt advanced technologies to facilitate using the OGD, and made it available technically, accessible, and readable to encourage use and reuse these data in their SMEs to get their benefits. But still the open government service providers and users of these data are facing many obstacles which limit continuous innovation, including a closed culture about data sharing, privacy policy, poor quality of data, technical constraints, data security policy, and others (Huijboon \& Roek, 2011). Open government data (OGD) is defined as a machine-readable information, especially government data that provided to others for using and obtaining different benefits of it (Mckinsey Consulting Institute, 2013). It is also defined as digital data available for public use, it is accessible, process able, used and reused, and redistributed in no /or at very low cost (Smith\& Sandberg, 2019), within the known conditions and principles of data availability, the most important of which: The data should be basic (primary), fully accessible, reachable, non-discriminatory, documented and verifiable, timely, non-proprietary, and manageable. Others define (OGD) as data owned by government institutions and published online (Smith \& Sandberg, 2019). So, data is freely accessible, used, reused or distributed free of charge and without any legal, technical, or financial restrictions. They are provided: complete, timely, non-discriminatory, readable, and not restricted by a particular license (https://opengovdata.org/, Accessed 25/10/2019). Open government data (OGD) is a recent practice in the development of services and public administration around the world, with the exception of personal, confidential, and sensitive data affecting national security. Governments and organizations that adopt open data approach have a heavy burden in protecting privacy and intellectual property, as well as setting standards that facilitate data flow (Mckinsey Consulting Institute, 2013). Despite the gains made by many developed countries because of their adoption of open data approaches, this approach has not been exploited or exploited in narrow spaces in many third world countries (World Bank Summit for Open Data 2012-2017). Recently, governmental institutions have been interested in launching open data services in order to improve services for the public and for the benefits of other sectors like (SMEs). Several initiatives in the Arab world have emerged to adopt open data approaches, as Jordan, Saudi Arabia's initiatives, Tunisia and others. So, data is considered as a valuable national resource and a strategic asset for the government, its partners and the public, its value increases by the time, and managing these data as strategic assets is a vital issue for the government.

\subsubsection{Principles of Open Government Data (OGD)}

In general, open government data should comply with the following principles (OpenGovData.org) (http://opendatatoolkit.worldbank.org/en/supply.html) (World Bank Summit for Open Data 2012-2017):

1. Public: government agencies must approve the openness of data to the extent permitted by law and subject to privacy, confidentiality, security or any other restrictions.

2. Accessibility: Availability of open data (OGD) in an accessible, editable, and open way so that it can be retrieved, downloaded, indexed and searched. Open data structures do not discriminate against any person or group of people and made available to the widest range of users and to the widest range of purposes, to the extent permitted by law.

3. Machine process able, to be readable, data should be organized to allow automated processing.

4. Description: (OGD) is fully described so that data users have sufficient information to understand their strengths and weaknesses, analytical limitations and security requirements, as well as how to address them. This includes using of complete metadata, comprehensive documentation of data elements, and dictionaries.

5. License-free: (OGD) should be provided under an open license, with no restrictions on its use and reuse.

6. Completion: (OGD) is published in primary forms (i.e. as collected from the source), with the highest possible accuracy

7. Timely: Open data is provided as quickly as possible, to maintain the data value.

\subsubsection{Benefits of open government data $(O G D)$}

As with any public initiatives, open data includes cost and effort. As such, government officials often care about the benefits of open data compared to the required levels of effort (http://opendatatoolkit.worldbank.org). Like other commodities, data has great potential to provide benefits. Some referred to the data as the new oil, because both data and oil had intrinsic value which must be "refined" or transferred to get their full benefits. In case of government data is accessed and reused, it enables individuals, organizations, and even governments to innovate and collaborate in new ways. In general, the benefits of open government data include:

1. (OGD) promotes transparency and reduces corruption, and it enables the government to monitor budgets and government spending.

2. Improves the quality of services provided by the public sector, by providing raw data to individuals, receiving feedback about government activities, or using them in other services. 
3. It leads to innovate and add economic value. Reuse of these data enhances social and entrepreneurial creativity, and serves SMEs alike, and thus achieving economic growth in general, in addition, it enables entrepreneurs understanding the market and provide products and services meeting all market requirements.

4. Improves efficiency, where open data reduces the cost of data acquisition for both government and private institutions specially for SMEs.

According to the Mckinsey Consulting Institute (2013), OGD, has generated considerable worldwide attention in its capacity to empower citizens, changing the government work, improving public service delivery, and give new economic benefits. According to the above report, only seven sectors can generate an additional value of (3-5 \$ trillion) per year as a result of open government data, these sectors are (education, transport, consumer products, electricity, oil and gas, health, and finance), which has already led to the emergence of hundreds of entrepreneurs. In addition, the emergence of OGD, helping SMEs in market segmentation, identifying new products and services, and improving the efficiency and effectiveness of operations.

\subsection{Businesses entrepreneurship}

\subsubsection{Businesses entrepreneurship: concepts and importance}

The term "entrepreneur" was used during the seventeenth century to refer to a person entering into a contractual agreement with the government to provide the services and products stipulated and determined by the contract, and any resulting profits or losses bearded by the entrepreneur. During the seventeenth century, French economist Richard Cantillon developed one of the early theories of entrepreneurship, and regarded the entrepreneur as a risk-taking person. Where he noted the contradictions between supply and demand and options like buying at a cheap price and selling at a higher price. He defined the entrepreneur as a trader or farmer who "buys at a certain price and sells at an undetermined price and bear the risk for that" (Pahuja \& Sanjeev, 2019). Alani et al. (2010) state that the entrepreneur term refers to a person who has the ability to discover and capture the opportunity, entrepreneur takes the risk to start the project then provides the necessary resources and capabilities to work and add value to the products, services, method and procedures. Therefore, the entrepreneur is working to find what is new and distinctive to meet the needs and desires of customers, where the result is either the acquisition of a tangible and intangible benefits, or exposure to moral and material loss. So, entrepreneurship has evolved from the traditional concept that means explore business opportunities before others do, then adopt informal and modern patterns in management that upgrading the organizational entrepreneurship (Akinyemi \& Adejumo, 2018; Zidan, 2007). In the middle of the 20 ${ }^{\text {th }}$ Century, Joseph Schumpeter was the first economist focusing on the role of entrepreneurship in economic development through innovation. In his opinion, "The entrepreneur function is to reform or revolutionize the production process, by exploiting an invention process or a new technological method to produce a new commodity, or production a new one in a new way, finding a new supply source to buy material, or a new outlet for selling products" (Pahuja \& Sanjeev, 2019). Hisrich and Petrts (2002) stated that the classical school defines the entrepreneur as a person who accepts risks and dealing with risk in uncertain circumstances, and who employed his administrative capacity to exploit capital to gain profit by increasing productivity. On the other hand, the economic school defines entrepreneurship as an element of production that regulates and coordinates the production process in uncertain circumstances. One of the entrepreneurs of this approach is the economist Adam Smith who pointed out that the entrepreneur is the person who owns or supplies the capital and is a mediator between producers and consumers. After that, the Austrian approach developed the concept of entrepreneurship, and explained its functions and roles, such as creativity, innovation and creative thinking. Which means creating a new product that surpasses the previous one and leads to create new demand in the market, then increasing entrepreneurs' benefits. One of the most prominent leaders of this school also is Schumpeter, who defined the entrepreneurship as innovation, creative thinking and presenting an unprecedented technological innovation (Hisrich \& Petrts, 2002). Whereas "Entrepreneurship Network" refers to entrepreneurs, who organized formally or informally to increase the efficiency of their activities. Moreover, networking is considered an activity for entrepreneurs to obtain information about new entrepreneurial ideas and opportunities (Das \& Goswami, 2019). Although the entrepreneur and entrepreneurship mean different things to different people, there is agreement that entrepreneurial behavior involves taking initiatives, organizing and reorganizing, process available resources in innovative ways, and accepting risk in uncertainties with potential of success or failure (Mariotti \& Glackin, 2010). In addition, entrepreneurs are people who start their own business and work for their own benefit, and mostly they are the owners and employees of their companies (Mubarak, 2009). The entrepreneur behavior in uncertainty state about a possible profitability opportunity is often a judgmental decision, therefore, entrepreneurs decide to start working, even in risk and uncertain circumstances, yet they respond, innovate and interact through their entrepreneurial work with everything around them, and do their work in a dynamic and unremitting manner to increase their wealth (Mariotti \& Glackin, 2010). Another concept related to entrepreneurship is entrepreneurial orientation which refers to the style, practice, and decision-making model of entrepreneurial organizations. We conclude from the above that entrepreneurship is a key concept for exploiting opportunities that competitors cannot observe. Many scientists agree that entrepreneurial orientation is a combination of creativity, proactive, and risk tolerance. Based on the above-mentioned, there are a number of features distinguishes entrepreneurs such as (Cowdrey, 2018): a clear and achievable vision, Self-awareness, confidence, Self - motivation, prepare to take calculated risks, the desire to listen to others, lack of fear of failure, and desire to hard working. Entrepreneurs or owners of (SMEs) are considered the solid foundation for any strong economy. East Asia, Brazil, Turkey and even major countries have reached their current position now because they started from scratch, and helped and encouraged small projects such as working from home, and providing care to those who have the opportunity to develop and grow a small business, then they continued to provide support to those who have the opportunity to be a medium-sized company until they now have giant entities in the world economies. 


\subsubsection{Dimensions of entrepreneurship}

The most important dimensions of entrepreneurship addressed by theoretical literature of management are (Andriopoulos \& Dawsonm, 2009):

1. Creativity: Creativity is a process that reflects a consistent trend to participate in/ and support new ideas, modernity, experimentation, and processes that may lead to new products, services or new technological processes.

2. Innovation: Innovation is the beneficial investment of new ideas and the process of transforming them into useful and usable products, processes and services. Innovation is strongly associated with business growth and most forms of economic growth in recent decades are due to innovation. New ideas create new businesses.

3. Risk-taking: risk taking is the combination of risk and opportunity, with focusing on avoiding or reducing risks, hedging them when looking for opportunities by understanding risks and how to deal with them.

4. Proactive and initiative: means proactive tendencies and self-initiation to start. Finding of proactive and initiator individuals is very important for management of organizations to discriminate, adopt, and support them (Lowe\& Marriott, 2006).

5. Seize opportunities: Entrepreneurial businesses can gain opportunities through creativity and innovation in products and services, which enable capturing customers and attracting their attention and loyalty. Entrepreneurship is the pursuit of opportunity, regardless of permanent availability of resources. The more the organization rearranges its resources, responds to the opportunities available, invests them intelligently, and acquires them before the competitors, the more they progress and distinct over competitors (Lowe\& Marriott, 2006).

6. Self-renewal: It reflects and translates the state of change, renewal, and transformation in organizations in an ongoing process, by renewing the main ideas on which the organization is based (Guth \& Ginsberg, 1990).

\subsubsection{The entrepreneurship in Arab countries}

SMEs in the third world stay behind the competitive and powerful companies, because of the ability of the last large ones to own and use technology, share data, and cooperate with regional and global partners. Other reasons also related to their ability to invest in research and development, use of digital and technological platforms, and ability to invest in human resources (Hisrich \& Petrts, 2002). Most Arab countries live in a poor economic and unstable political conditions. In addition, the current reality of entrepreneurship in the Arab countries as a whole is still in need of development and support in order to encourage young entrepreneurs to transform their ideas, initiatives, and opportunities into successful and productive projects. They need to provide them with a conducive and encouraging environment (Kuratko\& Hodgetts, 2001). Jordan as one of these countries, which has efficient and skilled human resources who have high abilities and aspirations to improve their economic conditions; entrepreneurship is one and most important mean to do this (Malkawi, 2017; Al-Khasawneh \& Malkawi, 2018). The success of entrepreneurial endeavors has a major impact on the economy of any country, they help to achieve individual aspirations and achieve goals such as financial gains, self-realization, and social identification. Since we still living in the age of enterprises development in the Arab world in general and Jordan in particular, entrepreneurship and entrepreneurs play a great role in economic development, so entrepreneurship and entrepreneurs need to be encouraged by educational institutions, government, and other civil community organizations. There are a large number of young entrepreneurs, who have no prior experience, they need assistance and facilitation for access to finance and administrative and technical support (Malkawi et al., 2017). For these reasons and others, increasing funding opportunities, improving infrastructure, providing less stringent labor systems, and open government data to them can contribute in improving the competitiveness of SMEs. Thus, this requires urgent action where studies indicated that, there are five factors hinder the development of entrepreneurship referred to (Moghaddam\& Izadi, 2019): financial problems, market orientation, lack of data, poor and inappropriate business environment, and lack of government supportive policies, and this study comes to support one of the most important of these reasons which is lack of data.

\subsubsection{Relationship between open data and business entrepreneurship}

Open government data is increasingly linked to the creation of new products and services, as well as helping companies to develop new insights and knowledge. Although open data innovation takes place in organizations of all sizes, entrepreneurs and startups (SMEs) are critical stakeholders in harnessing the potentials of open government data, by creating new open data base products, services, and new business models. Entrepreneurs are known for their creativity and their ability to turn ideas into successful businesses. So, more and more entrepreneurs who have an open database business models rely on the availability and high quality data and public sector information. Therefore, OGD has a huge impact in enabling entrepreneurs to have opportunities in creating new business models, products and services. (https://www.europeandataportal.eu/en/highlights/open-data-and-entrepreneurship).

Such (SMEs) reinforce the public debate about the economic impact of open data. Through their business activities, they offer the direct benefits of open data to the economy as a whole not least job creation to reduce unemployment and supporting national economy for each country. Entrepreneurs work as data analysts and brokers, software developers and other datarelated professionals make up an important group of new users. So, by introducing open database products and services, public institutions are convinced for further investment in open data programs. Moreover, small innovative startups that work with open data may pave the way for large corporations and public institutions to adopt new open data solutions. It is also important 
to continue to encourage and attract startups, by providing them with support opportunities that go beyond financing to supportive legislations, open government data availability and so on (https://www.europeandataportal.eu/en/highlights/opendata-and-entrepreneurship). Therefore, the relationship between open government data and business entrepreneurship is dual in its form. Entrepreneurs and open data mutually reinforce one another. Open data fosters entrepreneurship on the one hand, and entrepreneurs boost open data developments on the other hand.

\section{Previous studies}

Study of Mckinsey Consulting Institute (2013) aimed to determine the contribution of open government data to economic values of seven main sectors (education, transport, consumer products, electricity, oil and gas, health, and finance) and concluded that open data contributes ( 3 - 5 trillion dollars) annually in these sectors. The data liquidity and adoption of the open data approach encourage entrepreneurs to innovate, create, and serve small, medium and large companies in surveying the markets and providing products and services suitable for market needs. Malkawi (2017) aimed to know how to enhance entrepreneurship through E-Commerce adoption at (SMEs) in Jordan. The study concluded that: (SMEs) use E-Commerce at high rates, entrepreneurship also high, there is a statistical effect of E-Commerce on entrepreneurship as a whole and on all its components in Jordanian (SMEs), and recommended (SMEs) and entrepreneurs to expand using E-Commerce in their work. Walker and Simperl (2018) suggested that exciting and useful products and services based on open data are part of daily life, and emerging companies that develop their data create valuable new jobs. There are distinct approaches and programs that focus on supporting this development, and support entrepreneurs who share open data. It is also clear that open data cannot simply deployed "in a vacuum" and that businesses transactions are necessary to create the sustainability of open data. Mergela et al. (2018) aimed to examine the role of open government data in the process of creation and innovation in US cities through two dimensions: internal / external and / product / process through interviews with 15 mayors, results concluded that the impact of open government data on the creativity of external products was greater than the internal applications, websites, and new services, and recommended increasing government efforts in the area of open data through structural, procedural and cultural changes so as to government initiatives about open data succeed. Sedkaoui (2019) indicated that the value added of big data is the ability to identify useful data and transform it into usable information. This study shows the need for new analytical thinking and computational skills for the new generation of entrepreneurs to deal with the big data challenges to create new opportunities from these data. The paper also identifies the role of big data and the transformation of possibilities into realistic opportunities.

\section{Methodology}

\subsection{Objective of the Study}

The general purpose of this study is to find out the role of open government data on business entrepreneurship at Jordanian (SMEs)-Irbid State.

\subsection{Hypothesis}

The main hypothesis: There is a significant positive effect of open government data on business entrepreneurship at Jordanian (SMEs)-Irbid State.

Minor hypotheses are:

P1: There is a significant positive effect of technological issues on business entrepreneurship at Jordanian (SMEs)-Irbid State. P2: There is a significant positive effect of quality of data on business entrepreneurship at Jordanian (SMEs)-Irbid State.

\subsection{Study model}

Fig. 1 shows the proposed study (dependent and independent variables).

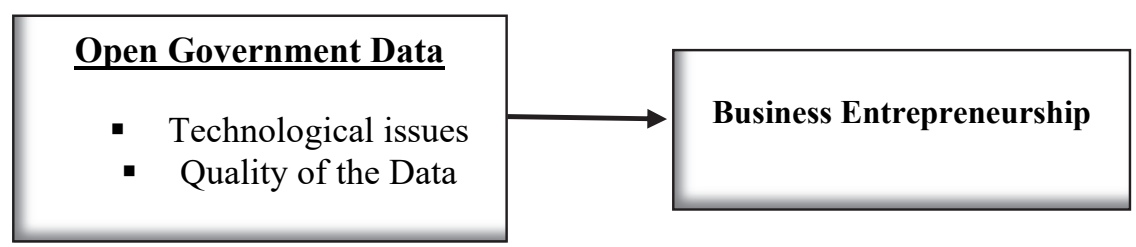

Fig. 1. Study model

\subsection{Data collection}

The study used descriptive analytical methodology. So, researchers depended on Mckinsey Consulting Institute (2013), Khasawneh (2011), Alraga and Malkawi (2015) and others to develop a questionnaire for collecting data from the study sample. Face and content validity were done by faculty members their major related to the subject of the study. Next, result items ordered randomly for each construct and the Likert 1-5 scale used for measuring the responses. 


\subsection{Study Population and Sample}

The study population consisted of all SMEs in Irbid state- Jordan. A non-probability sample (suitable sample) was selected because of the absence of an integrated database of entrepreneurs and start-up entrepreneurs and the size of the community could not be determined. So (600) questionnaires were distributed to collect the field data from SMEs and (536) valid questionnaires of them were recovered $(89 \%)$.

\section{Data analysis}

The aim of this study is to investigate the role of open government data on business entrepreneurship. We used two sub variables to reflect the role of open government data on business entrepreneurship including technology used to disseminate open government data and quality of open government data. This study predicts that open government data variables have effects on business entrepreneurship. To achieve the main objective of this study we performed several analyses as it appears in the next sections.

\subsection{Descriptive statistics}

In this section, we present demographic characteristics of the respondents and descriptive statistics regarding the research variables. As mentioned above (536) valid responses were recovered, where; 498 males, 38 females, 216 less than 30 years old, 194 between 30 and less than 40 years old and the rest were over 40 years. Diploma and less were 62,428 bachelors and the rest were postgraduate. 54 of them less than 5 years' experience, 346 from 5 to less than 10 years, and 136 more than 10 years' experience. Table 1 shows the descriptive statistics of the variables investigated in this study as assessed by the respondents. The respondents' perception for each variable is assessed based on its mean. The mean is judged as low if $(<2.33)$, moderate if $(>=2.33)$ and $(<=3.67)$, and high if mean $(>3.67)$. Having this in mind, the respondents of this study generally assessed open government data as moderate with total mean (3.51). In addition, they assessed their open government data as high in term of technology used and low in quality of data opened. In addition, the level of business entrepreneurship was moderate as the total mean is (3.59). Table 1 shows descriptive statistics.

Table 1

Descriptive statics of the variables

\begin{tabular}{|c|c|c|}
\hline Items & Mean & St. dev. \\
\hline Technology used to disseminate open government data & 3.73 & 0.67 \\
\hline Quality of open government data & 3.30 & 0.84 \\
\hline Open government data (total) & 3.51 & 0.66 \\
\hline Businesses Entrepreneurship & 3.59 & 0.78 \\
\hline
\end{tabular}

As shown in Table 1 technology as a sub variable for open government data come in a high level with mean (3.73) and standard deviation (0.72), whereas data quality in a moderate level with mean (3.30) and open government data as a whole in moderate level (3.51) which needs more interest from government. Business entrepreneurship comes in a moderate level also with arithmetic mean (3.59). Appendix 1 shows this in more details. Before regression analysis, we examined for the normal distribution of the data, Multicollinearity issue, and the internal consistency of the variables to confirm the quality of data examined. We estimated the data Skewness and Kurtosis to assess the normality of data. As shown in Table 2, the values of Skewness and Kurtosis for each variable are less than the threshold of absolute value of (2). This suggests that our data is normally distributed. For Multicollinearity issue, Variance Inflation Factor (VIF) is a frequently used to inspect Multicollinearity. According to the rule of thumb, a VIF value of (5) and higher indicates a potential problem of Multicollinearity (Hair \& Anderson, 2010). The results presented in Table 2 show that the VIF values vary between (1.176 and 2.251) which less than the cut-off value of (5). Therefore, the proposed path model has no Multicollinearity issue.

Table 2

Skewness, Kurtosis, and VIF of all variables

\begin{tabular}{lllllr}
\hline Variable name & $\begin{array}{l}\text { Skewness } \\
\text { Statistic }\end{array}$ & Std. Error & $\begin{array}{l}\text { Kurtosis } \\
\text { Statistic }\end{array}$ & Std. Error & TIF \\
\hline Total Open government data & -0.487 & 0.283 & 0.363 & 0.559 & 1.243 \\
Business entrepreneurship & -0.536 & 0.279 & 0.582 & 0.552 & 1.176 \\
Technology & -0.330 & 0.277 & -0.623 & 0.548 & 1.904 \\
Data quality & -0.655 & 0.277 & 1.009 & 0.548 & 2.251 \\
\hline
\end{tabular}

We assessed the internal consistency by estimating the Cronbach's Alpha for each variable, the values range from 0.74 for OGD, 0.83 for business entrepreneurship, and 0.84 for the tool as a whole, which are above the threshold value 0.70 . Therefore, our data are credible and can be used in regression analyses safely.

\subsection{Hypotheses testing}

To examine our hypotheses, we run two models. In the first model, we examine the main hypothesis, which predicts a positive and significant relationship and effect between open government data and business entrepreneurship. In the second model, we examine the effect of each dimension of open government data including technology and data quality. As shown in Table 3 , the result of the first model indicates that open government data as a whole explains about $0.42\left(R^{2}=0.42\right)$ of the variance in the business entrepreneurship, and the F-test is significant at $(p<0.00)$. This suggests that open government data as a whole 
have a significant effect on business entrepreneurship as a whole. The sign of the business entrepreneurship's standardized coefficient is positive. This suggests that the relationship is positive and significant at $\mathrm{P}<0.05$. This result offers a sufficient evidence to accept the main hypotheses in this study.

Table 3

The result of OLS regression between open government data and business entrepreneurship

\begin{tabular}{|c|c|c|c|c|c|}
\hline Model & F test & $\mathrm{R}^{2}$ & standardized coefficients (Beta) & $\mathrm{t}$ & Sig. \\
\hline $\begin{array}{ll}1 & \text { (Constant) }\end{array}$ & & & & 7.152 & 0.000 \\
\hline Overall open government data & $14.52 * * *$ & 0.42 & 0.492 & 4.521 & 0.000 \\
\hline
\end{tabular}

The result of the second model, which examines the effect of each dimension of open government data on business entrepreneurship, is presented in Table 4. The overall F-test is significant at $(p<0.00)$, indicating that the dimensions of open government data are significant jointly. The model explains about 0.42 as reflected by $\mathrm{R}^{2}$ value. Individually, the result shows that the standardized coefficients (Beta) of technology is not significant at $p<0.05$. This indicates that technology individually has no effect on business entrepreneurship. Accordingly, we reject the sub hypotheses (P1) that technology has positive effect on business entrepreneurship. Moreover, the same table shows that the standardized coefficients (Beta) of data quality is significant at $\mathrm{p}<0.05$, this indicates that data quality individually has effect on business entrepreneurship. Accordingly, we accept the sub hypotheses (P2) that data quality has positive effect on business entrepreneurship. This suggests that as data quality increases, business entrepreneurship increase.

Table 4

The result of OLS regression between each dimension of open government data and business entrepreneurship

\begin{tabular}{|c|c|c|c|c|c|}
\hline Model & F test & $\mathrm{R}^{2}$ & Standardized coefficients (Beta) & $\mathrm{t}$ & Sig. \\
\hline (Constant) & $8.31 * * *$ & 0.42 & & 7.152 & .000 \\
\hline Technology & & & .073 & .724 & .462 \\
\hline Data quality & & & -.253 & -1.725 & .021 \\
\hline
\end{tabular}

*** signifies significant at 0.00

\section{Results}

The main results of the study are:

1. The level of open government data in Jordan from the view point of SMEs-Irbid state is moderate, so it needs to be improved through new government initiatives which is recommended by many studies like (Mckinsey, 2018) (World Bank Summit for Open Data 2012-2017).

2. The level of businesses entrepreneurship in Jordanian SMEs -Irbid state is also moderate, which assures the necessity to concentrate on supporting SMEs as a main sector in Jordanian economy and this is compatible with (Malkawi, 2017).

3. There is a significant positive effect at $(\alpha \leq 0.05)$ of open government data on business entrepreneurship at SMEs in Jordan-Irbid state, and interpreted (42\%) of variance at business entrepreneurship. This assures the role of (OGD) on business entrepreneurship, which support results of previous research like (Mergela et al., 2018; Sedkaoui, 2019).

4. There is a significant positive effect at $(\alpha \leq 0.05)$ of data quality variable on businesses entrepreneurship individually, whereas technologies used have no effect

\section{Discussion and recommendations}

We believe that organizations in general; and (SMEs) in particular now a days realize the role of open government data in achieving competitive advantage and survival, and adoption of open government data from government and these businesses are considered as necessity at this time. Clear understanding and alignment of open government data for business entrepreneurship is essential to realize the potential benefits for (SMEs). In our study, we examined the role of independent variable (open government data) on the dependent variable (business entrepreneurship) from entrepreneurs' point view at Jordanian Irbid State SMEs. The findings of this study indicate that the level of open government is moderate, business entrepreneurship also moderate. There is a positive effect of open government data on business entrepreneurship. So entrepreneurial businesses should aware the benefits which can be obtained by depending on open government data and realize the role of open government data in today's business. Therefore, the first implication of this study is that adoption of open government data is the key to success in business entrepreneurship; this would lead to facilitate open government data adoption successfully. Secondly, because expected benefits have a positive effect on the adoption of open government data, entrepreneurs at (SMEs) in Jordan-Irbid state should benefit from these opportunities and maximize exploiting open government data in their businesses. Thirdly, because of survival and competitive pressures; (SMEs) should take into account that open government data would help them to succeed and compete. So, researchers can say; the originality of this study comes from the importance of open government data in today's economy, and form studying an important issue whether business entrepreneurship affected by the open government data adoption. It is unique in its tied of open government data and business entrepreneurship in Jordanian 
economy which depends on SMEs to deal with poor economic conditions. In light of the above researchers recommend government to expand the level of applying open government data initiatives and improve data quality as indicated (3.51) in a moderate level, and entrepreneurs to increase the level of relying on open government data to get information about materials, markets, competitors, legislations and so on then get benefits for their businesses. Future research can be conducted at open government data to find its effect on business entrepreneurship with the same or other variables, or its effect on other sectors.

\section{References}

Akinyemi, F. O., \& Adejumo, O. O. (2018). Government policies and entrepreneurship phases in emerging economies: Nigeria and South Africa. Journal of Global Entrepreneurship Research, 8(1), 35.

Al-Khasawneh, A. L., Malkawi, N. M., \& AlGarni, A. A. (2018). Sources of recruitment at foreign commercial banks in Jordan and their impact on the job performance proficiency. Banks \& Bank systems, 13(2), 12-26..

Andriopoulos, C. \& Dawsonm, (2009). Managing change, creativity and innovation. London: Sage. Beer, M and Nohria, N. (1998). Cracking the Cod of change. Harvard Business Review, 78(3), 133-141.

Alraja, M. N., \& Malkawi, N. M. (2015). E-business adoption in banking sector: Empirical study. Indian Journal of Science and Technology, 8(27), 1-5.

Cowdrey, R. (2018). Creating an Entrepreneurial Mindset. $2^{\text {nd }}$ ed., Roger Cowdrey MIBC \& bookboon.com, ISBN 978-87403-2313-9.

Deloitte, (2017). Shaping the Future of Open Data.

Das, M., \& Goswami, N. (2019). Effect of entrepreneurial networks on small firm performance in Kamrup, a district of Assam. Journal of Global Entrepreneurship Research, 9(1), 7.

Guth, W. D., \& Ginsberg, A. (1990). Guest editors' introduction: Corporate entrepreneurship. Strategic Management Journal, 11, 5-15.

Hair, J. F., Black, W. C., Babin, B. J., \& Anderson, R. E. (2010). Confirmatory factor analysis. Multivariate Data Analysis, 7th ed.; Pearson Education, Inc.: Upper Saddle River, NJ, USA, 600-638.

Hisrich, D. H., \& Peters, M. D. (2002). Entrepreneurship. $5^{\text {th }}$ ed., McGraw-Hill Higher Education.

http://opendatatoolkit.worldbank.org/en/supply.html, Accessed 20/10/2019.

https://opengovdata.org/, Accessed 25/10/2019.

https://www.europeandataportal.eu/en/highlights/open-data-and-entrepreneurship, Accessed 27/10/2019.

Huijboom, N., \& Van den Broek, T. (2011). Open data: an international comparison of strategies. European journal of ePractice, 12(1), 4-16.

Khasawneh, Akif L. (2011). Managing of innovation and creativity at the business organizations. Dar Hamed publishing center, Amman, Jordan

Kuratko, D. F., \& Hodgetts, R. M. (1995). Entrepreneurship: A contemporary approach. Dryden Press.

Lowe, R., \& Marriott, S. (2006). Enterprise: entrepreneurship and innovation concepts, contexts and commercialization. Jordan Hill, (1sted), Oxford OX2 8DP30 Corporate Drive, Suite 400, Burlington, MA 01803, USA.

Malkawi, N. (2016). Executing Knowledge Management 2.0 (KM 2.0) through Web 2.0-Applied Study at Jordanian Insurance Companies. International Journal of Business and Social Science, 7(10).

Malkawi, N. (2017). "Enhancing Entrepreneurship Through E-commerce Adoption -Applied Study at Small CompaniesIrbid- Jordan International Journal of Research in Management, Economics and Commerce (IJRMEC), Volume 07 Issue 1, January 2017, PP. 46-55.

Malkawi, N. M. M. A., Alraja, M. N., \& Alkhayer, T. (2010). Information systems auditing applied study at banks listed in the Damascus Stock Exchange Syria. European Journal of Economic Financial Administration Science, $21,119$.

Malkawi, N., Obeidat, A. M., \& Halasa, A. (2017). Achieving Performance Excellence through Cloud Computing Atmosphere-Applied Study at Zain Telecommunications Company-Jordan. International Review of Management and Business Research, 6(1), 229-243.

Malkawi, N. M. (2018). using electronic human resource management for organizational excellence-case study at social security corporation-Jordan. International Journal of Engineering Technologies and Management Research, 5(5), 146-166.

Mckinsey Consulting Institute (2013). Open Data: Unlocking innovation and performance with liquid information. Retrieved from http://www.mckinsey.com/business-functions/digital-mckinsey.

Malkawi, N. M., \& Halasa, A. (2016). Exploiting electronic social networks in educational process: Study at Universities in Irbid State-Jordan. Journal of Education \& Social Policy, 3(5), 96-105.

Mergel, I., Kleibrink, A., \& Sörvik, J. (2018). Open data outcomes: US cities between product and process innovation. Government Information Quarterly, 35(4), 622-632.

Malkawi, N. M., Al Omari, K., \& Halasa, A. (2018). Intellectual capital as a core competency for competitive advantage: A case study. Journal of Digital Information Management, 16(4), 146-166.

Mariotti, S., \& Glackin, C. (2010). Entrepreneurship starting and operating a small business. $2^{\text {nd }}$ ed., Prentice Hall.

Mukherjee, S. (2018). Challenges to Indian micro small scale and medium enterprises in the era of globalization, https://doi.org/10.1186/s40497-018-0115-5.

OpenGovData.org. the 8 Principles of Open Government Data, Accessed 15/1/2020.

Pahuja, A., \& Sanjeev, R. (2019). Introduction to Entrepreneurship, Institute of Management Studies, Date Written: April 10, 2015. 
Rezaei-Moghaddam, K., \& Izadi, H. (2019). Entrepreneurship in small agricultural quick-impact enterprises in Iran: Development of an index, effective factors and obstacles. Journal of Global Entrepreneurship Research, 9(1), 17. https://doi.org/10.1186/s40497-018-0133-3.

Sedkaoui, S. (2019). How data analytics is changing entrepreneurial opportunities? Emerald Publishing Limited 2016 Published by Emerald Publishing Limited Licensed re-use rights only. Journal of Innovation Science, 10(2).

Smith, G., \& Sandberg, J. (2018). Barriers to innovating with open government data: Exploring experiences across service phases and user types. Information Polity, 23(3), 249-265.

Walker, J., \& Simperl, E. (2018). Open Data and Entrepreneurship, Last update: February 2016, www: http://www.europeandataportal.eu/@:info@europeandataportal.eu.

World Bank Summit for Open Data 2012-2017.

Zidan, A. (2007). Entrepreneurship: The Driving Force of National Economies, Arab Organization for Administrative Development Publications, Cairo.

Zuiderwijk, A., Shinde, R., \& Janssen, M. (2019). Investigating the attainment of open government data objectives: Is there a mismatch between objectives and results?. International Review of Administrative Sciences, 85(4), 645-672.

Appendix 1. Descriptive statics of the study variables

\begin{tabular}{|c|c|c|c|}
\hline NO. & Items & Mean & $\begin{array}{l}\text { St. } \\
\text { dev. }\end{array}$ \\
\hline 1 & The technology used facilitates access to open government data & 3.90 & 0.54 \\
\hline 2 & The technology used facilitates searching process of open government data & 3.90 & 0.52 \\
\hline 3 & The technology used facilitates reading and using data automatically. & 3.90 & 0.48 \\
\hline 4 & The technology used keeps data security from tampering or vandalism & 3.60 & 0.56 \\
\hline 5 & The technology used facilitates data reuse and redistribution when needed & 3.70 & 0.58 \\
\hline 6 & There is a clear electronic index indicating the content of open government data & 3.60 & 0.54 \\
\hline 7 & Open government data platforms facilitate secure data access & 3.50 & 0.45 \\
\hline \multicolumn{2}{|c|}{ Technology used to disseminate open government data } & 3.73 & \\
\hline 8 & $\begin{array}{l}\text { Government data is available to the extent permitted by law, with regard to privacy, } \\
\text { confidentiality, and any restrictions relating to the public interest }\end{array}$ & 3.70 & 0.91 \\
\hline 9 & Government data is available in a machine-readable form & 3.30 & 0.73 \\
\hline 10 & $\begin{array}{l}\text { The data is described in full, showing the strengths, weaknesses and analytical limitations } \\
\text { and how to process them }\end{array}$ & 3.40 & 0.59 \\
\hline 11 & Open data is available in a usable and reusable manner. & 3.70 & 0.53 \\
\hline 12 & Open government data has a high degree of completeness & 3.00 & 0.51 \\
\hline 13 & Open government data is highly reliable and precise & 2.70 & 0.82 \\
\hline 14 & Open data is available in a timely manner to remain new and valuable & 3.50 & 0.56 \\
\hline 15 & $\begin{array}{l}\text { There is a contact point (platform) to help in the use data and responding complaints } \\
\text { related to open data requirements. }\end{array}$ & 3.20 & 0.58 \\
\hline 16 & Enclose with the open government data a license to use it & 3.30 & 0.54 \\
\hline 17 & Open government data is available in a non-discriminatory manner & 3.20 & 0.45 \\
\hline \multicolumn{2}{|c|}{ Quality of open government data } & 3.30 & \\
\hline \multicolumn{2}{|c|}{ Open government data } & 3.51 & \\
\hline 18 & $\begin{array}{l}\text { Open government data improves creativity and innovation in entrepreneurship (new } \\
\text { products, new services, processes and new business models) }\end{array}$ & 3.60 & 0.84 \\
\hline 19 & Open Data helps entrepreneurial businesses reduce risks and ease of handling them & 3.80 & 0.595 \\
\hline 20 & $\begin{array}{l}\text { Open government data enables entrepreneurial businesses to obtain a stock of data and } \\
\text { information at no cost. }\end{array}$ & 3.90 & 0.64 \\
\hline 21 & Open data helps entrepreneurial businesses to achieve proactive and initiative results & 3.40 & 0.80 \\
\hline 22 & Open government data enables entrepreneurial businesses to capture opportunities & 3.70 & 0.83 \\
\hline 23 & Entrepreneurial businesses rely on open government data to penetrate markets & 3.30 & 0.66 \\
\hline 24 & Open government data enables entrepreneurs to establish new entrepreneurial businesses. & 3.40 & 0.78 \\
\hline \multicolumn{2}{|r|}{ Businesses Entrepreneurship } & 3.59 & \\
\hline
\end{tabular}

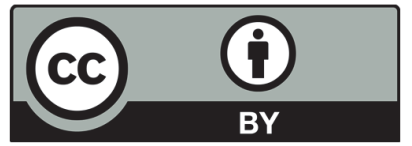

(C) 2021 by the authors; licensee Growing Science, Canada. This is an open access article distributed under the terms and conditions of the Creative Commons Attribution (CC-BY) license (http://creativecommons.org/licenses/by/4.0/). 